\title{
Cement pulmonary embolism as a complication of percutaneous vertebroplasty in cancer patients
}

\author{
Asem Mansour ${ }^{1 *}$ (D) Nayef Abdel-Razeq ${ }^{2}$, Hussein Abuali ${ }^{1}$, Mohammad Makoseh ${ }^{3}$, Nouran Shaikh-Salem³, \\ Kamelah Abushalha ${ }^{3}$ and Samer Salah ${ }^{3}$
}

\begin{abstract}
Background: Vertebroplasty is a minimally invasive procedure commonly performed for vertebral compression fractures secondary to osteoporosis or malignancy. Leakage of bone cement into the paravertebral venous system and cement pulmonary embolism (CPE) are well described, mostly in patients with osteoporosis. Little is known about the clinical sequelae and outcomes in cancer patients. In this study, we report our experience with CPE following vertebroplasty performed in cancer patients.

Methods: Records of all consecutive cancer patients who underwent vertebroplasty at our institution were retrospectively reviewed. The procedure was performed via percutaneous injection of barium-opacified polymethyl-methacrylate cement.

Results: A total of 102 cancer patients with a median age of 53 (19-83) years were included. Seventy-eight (76.5\%) patients had malignant vertebral fractures, and 24 (23.5\%) patients had osteoporotic fractures. Cement PE was detected in 13 (12.7\%) patients; 10 (76.9\%) patients had malignant fractures, and the remaining three had osteoporotic fractures. Cement PE was mostly asymptomatic; however, 5 (38.5\%) patients had respiratory symptoms that led to the diagnosis. Only the five symptomatic patients were anticoagulated.

Cement PE was more common with multiple myeloma (MM); it occurred in 7 (18.9\%) of the 37 patients with MM compared with only three (7.3\%) of the 41 patients with other malignancies. No difference in incidence was observed between patients with osteoporotic or malignant vertebral fractures.

Conclusions: Cement PE is a relatively common complication following vertebroplasty and is mostly asymptomatic. Multiple myeloma is associated with the highest risk. Large-scale prospective studies can help identify risk factors and clinical outcomes and could lead to better prevention and therapeutic strategies.
\end{abstract}

Keywords: Vertebroplasty, Cement, Pulmonary embolism, Cancer, Osteoporosis

\section{Background}

Vertebral body compression fractures are common, especially among elderly patients. The high prevalence of osteoporosis and cancer in this age group is a major contributing factor [1-3].

In addition to severe pain requiring hospital admission and parenteral opioids, these fractures can cause neurological deficits, height loss and kyphosis with associated restrictive pulmonary disease $[4,5]$.

\footnotetext{
* Correspondence: amansour@khcc.jo

${ }^{1}$ Department of Radiology, King Hussein Cancer Center, Amman, Jordan

Full list of author information is available at the end of the article
}

Vertebroplasty is a minimally invasive procedure that is commonly performed for vertebral compression fractures secondary to both osteoporosis and malignancy [6]. The procedure is performed under image guidance and involves the injection of a cement polymer, commonly polymethylmethacrylate (PMMA), into the vertebral body to confer improved stability and pain relief $[7,8]$. Vertebroplasty was first introduced at the University Hospital of Amiens, France, in 1984, when it was used to augment the post-resection defect of a benign spinal tumor [9]. Since then, it has become an 

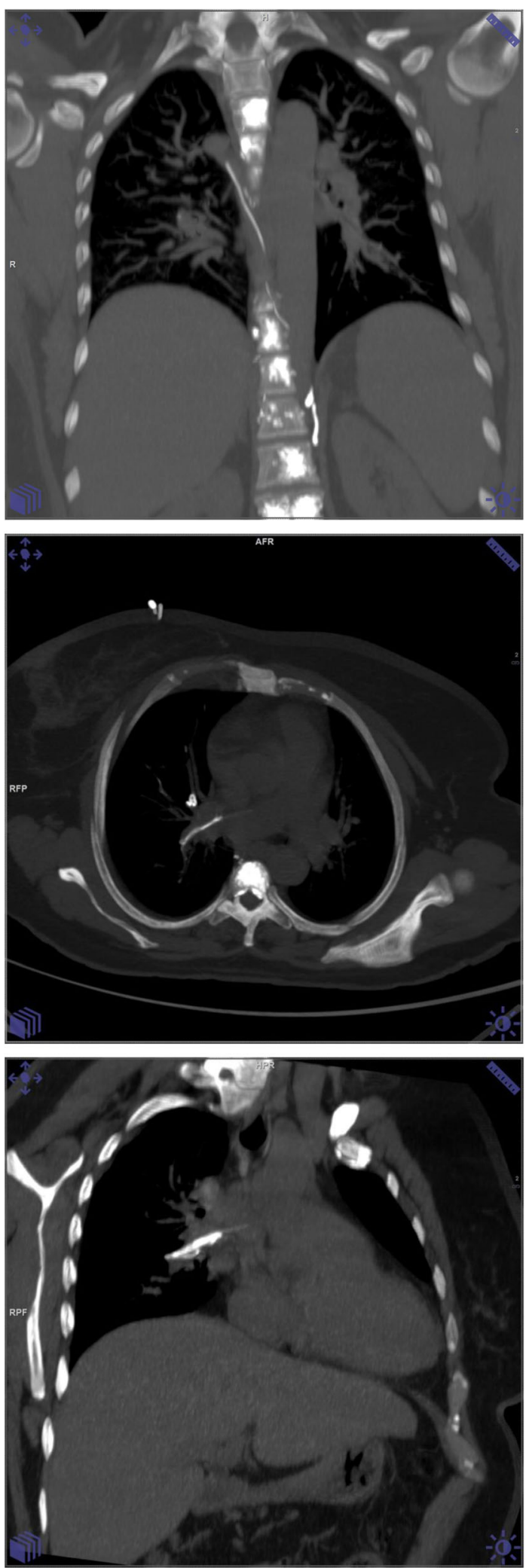

Fig. 1 Selected coronal image with maximum intensity projection of unenhanced chest $C T$ showing multilevel vertebral augmentation by cement. There is a branching linear density along the course of the lumber veins and the azygus/hemiazygus system representing cement leak/ intravasation. Axial and coronal oblique MIP images are showing a similar linear density in the right main pulmonary artery extending to the right superior segmental branch of the right lower lobe representing cement pulmonary emboli

increasingly recommended therapeutic intervention due to its high efficacy and safety [10].

Vertebral bodies are highly vascularized and form a valveless network with the paravertebral and extradural venous plexuses. Vertebral compression fractures enhance venous drainage and facilitate migration of cement fragments into the systemic venous circulation. Leakage of bone cement into the paravertebral venous system is well described (Fig. 1) [11]. Cement pulmonary embolism (cPE) is a well-recognized complication of vertebroplasty in patients with traumatic, osteoporotic, and metastasis-induced compression fractures [12-14]. The clinical implications and complications associated with such embolisms, especially in cancer patients, are poorly characterized.

In this study, we report our experience with vertebroplasty performed for vertebral fractures in cancer patients. We also provide a literature review of published data regarding $\mathrm{CPE}$ in cancer and non-cancer patients.

\section{Methods}

This is a retrospective study in which the hospital's and the radiology department's databases were searched for both "vertebroplasty" and "CPE". The records of all patients who underwent vertebroplasty at our institution over the past ten years were reviewed. All imaging studies including computed tomography (CT) scans or plain chest radiographs that were performed following vertebroplasty for any indication were reviewed again by an experienced radiologist to assess for features of $\mathrm{cPE}$.

The following data were extracted from patients' charts and electronic medical records: gender, age at time of vertebroplasty, type and stage of cancer, number and location of vertebral metastases, status of the patient before vertebroplasty (ambulatory or hospitalized), and history of cardiac or pulmonary diseases diagnosed before the vertebroplasty. Moreover, we gathered data pertaining to imaging tools that were utilized for diagnosis of $\mathrm{cPE}$, clinical manifestations, details of treatment, hemodynamic sequelae associated with $\mathrm{cPE}$, and dates of last follow-up and death.

The procedure was performed under image guidance via a percutaneous injection of barium-opacified polymethylmethacrylate cement. 
Given its retrospective nature, our research was exempted from review by our Institutional Review Board (IRB).

\section{Results}

A total of 102 patients underwent vertebroplasty during the study period and were included in this report. All had a pathology-confirmed diagnosis of cancer. The median age was 53 years (range: $19-83)$, and 57 (55.9\%) patients were female.

Pathological evaluation of the fractured vertebrae confirmed metastatic disease involvement in 78 (76.5\%) patients. The fractures in the other 24 (23.5\%) patients, many with active cancer, were due to osteoporosis. Vertebroplasty was performed in the lumbar spine in 57 (55.9\%) patients and in the thoracic spine in 16 (15.7\%) patients; $29(28.4 \%)$ patients had the procedure performed in both lumbar and thoracic vertebrae.

Multiple myeloma was the commonest primary cancer and was identified in 37 (36.3\%) patients, followed by breast cancer in $25(24.5 \%)$ patients and lymphoma in $13(12.7 \%)$ patients. Most patients (95.1\%) were ambulatory at time of vertebroplasty; only 5 were wheelchairbound. In addition to cancer, many patients had other comorbidities, including significant cardiac illness in 19 $(18.6 \%)$ patients and significant pulmonary disease in 9 (8.8\%) patients had (Table 1).

Cement PE was identified in 13 (12.7\%) cases; the median age of patients with cPE was 50 years (range: 31-81). Eleven (84.6\%) patients were diagnosed by CT scan (Fig. 2), while the other two patients had an initial suspicious finding on chest X-ray that was confirmed by a follow-up CT. All patients with confirmed cPE except one were ambulatory at the time of vertebroplasty.

The total number of levels injected was 252 (mean per patient: 2.47, median: 2). As such, the incidence of $\mathrm{cPE}$ is 5.2 episodes per 100 injections. Among the 13 patients with cPE, a total of 39 levels were injected (mean: 3.0, median: 3).

Cement PE was mostly asymptomatic, but 5 (38.5\%) patients had symptoms (dyspnea, chest pain, cough, tachycardia, hypoxia) that led to the diagnosis. Only the five symptomatic patients were anticoagulated; all were treated with low molecular weight heparin (LMWH) and none had any minor or major bleeding or any other complication related to anticoagulation. Ten $(76.9 \%)$ of the 13 patients had malignant vertebral fractures, while the other three $(23.1 \%)$ patients had osteoporotic fractures with no known vertebral metastasis. Details of the 13 patients are listed in Table 2.

Cement PE was more common among patients with MM compared to other malignancies; it occurred in seven of 37 (18.9\%) MM patients and 3 of 41 patients (7.3\%) with other malignancies $(\mathrm{HR}=0.338 ; 95 \% \mathrm{CI}$, $0.081-1.42 ; P=0.18$ ).
Table 1 Patients' characteristics

\begin{tabular}{|c|c|}
\hline \multicolumn{2}{|l|}{ Age } \\
\hline Median (years) & 53 \\
\hline Range (years) & $19-83$ \\
\hline \multicolumn{2}{|l|}{ Sex } \\
\hline Male & $45(44.1 \%)$ \\
\hline Female & 57 (55.9\%) \\
\hline \multicolumn{2}{|l|}{ Smoking history: } \\
\hline Smoker & $17(16.7 \%)$ \\
\hline Ex-smoker & $18(17.6 \%)$ \\
\hline Never smoked & $67(65.7 \%)$ \\
\hline \multicolumn{2}{|l|}{ Underlying cancer: } \\
\hline Multiple Myeloma & $37(36.3 \%)$ \\
\hline Breast & $25(24.5 \%)$ \\
\hline Lymphoma & $13(12.7 \%)$ \\
\hline Lung & $5(4.9 \%)$ \\
\hline Sarcoma & $4(3.9 \%)$ \\
\hline Prostate & $4(3.9 \%)$ \\
\hline Others & $14(13.7 \%)$ \\
\hline \multicolumn{2}{|l|}{ Timing of vertebral fracture: } \\
\hline Initial presentation & 57 (55.9\%) \\
\hline Disease recurrence & $45(44.1 \%)$ \\
\hline \multicolumn{2}{|l|}{ Comorbidities: } \\
\hline Hypertension & $32(31.4 \%)$ \\
\hline Diabetes mellitus & $26(25.5 \%)$ \\
\hline Cardiac disease & 19 (18.6\%) \\
\hline Pulmonary disease & $9(8.8 \%)$ \\
\hline \multicolumn{2}{|l|}{ Mobility: } \\
\hline Ambulatory & $97(95.1 \%)$ \\
\hline Wheel-chair bound & $5(4.9 \%)$ \\
\hline \multicolumn{2}{|l|}{ Underlying etiology and site: } \\
\hline No metastasis (Osteoporosis) & $24(23.5 \%)$ \\
\hline Vertebral metastasis ${ }^{\mathrm{a}}$ : & $78(76.5 \%)$ \\
\hline Cervical spines & $61(78.2 \%)$ \\
\hline Dorsal spines & $73(93.6 \%)$ \\
\hline Lumbar spines & 75 (96.2\%) \\
\hline
\end{tabular}

${ }^{\mathrm{a}}$ Total $>102$, reflecting multiple sites

The nature and etiology of vertebral fractures are also worth addressing. In all seven myeloma patients with $\mathrm{CPE}$, the fracture was related to malignant tumor infiltration but the two lymphoma cases were related to osteoporosis and not malignancy; both lymphoma cases were in elderly women (78 and 81 years old) who had received a significant amount of steroids as part of their lymphoma treatment.

The incidence of cPE was not different in patients with osteoporotic $(3 / 24,12.5 \%)$ or malignant $(10 / 78,12.8 \%)$ 

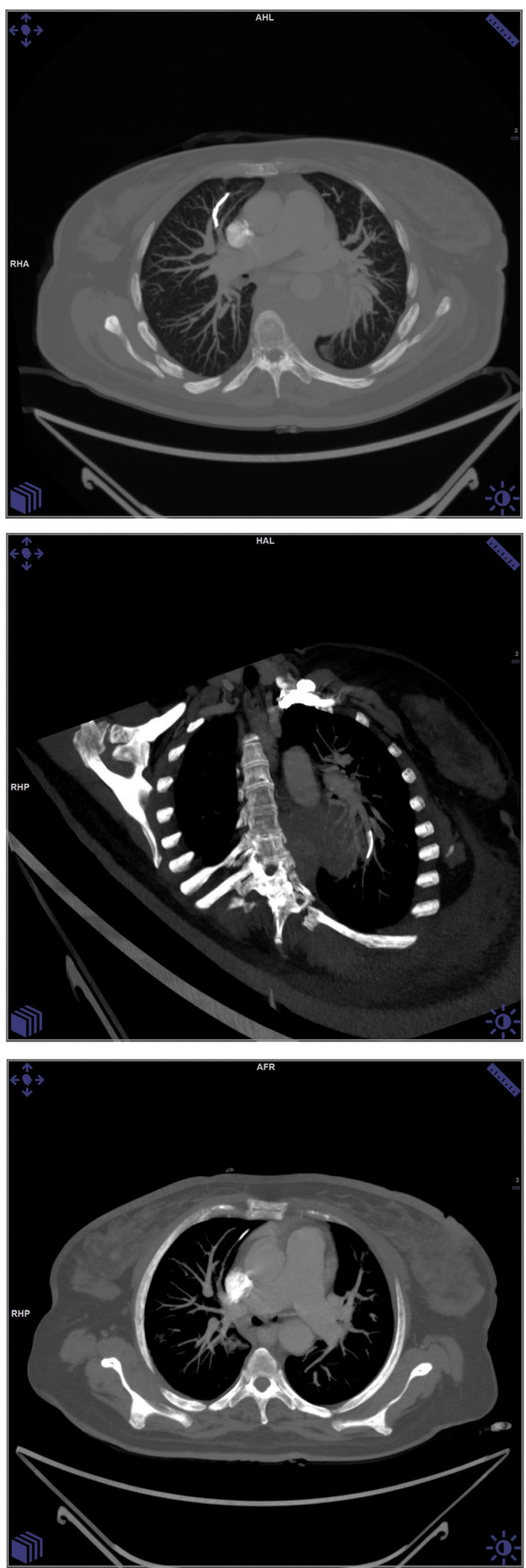

Fig. 2 Chest $C T$ with MIP showing a curvilinear density in the anterior subsegmental branch of Right Upper lobe indicating cement PE. Oblique coronal MIP image of the same patient showing cement PE in basal subsegmental branch of LLL

vertebral fractures $(\mathrm{HR}=0.972 ; 95 \% \mathrm{CI}, 0.244-3.86$; $P=0.99)$. However, patients with osteoporotic vertebral fractures were older, with a median age of 66 years compared to 51 years for patients with malignant fractures $(P=0.0076)$.

Survival following the vertebroplasty and associated cPE was variable; one patient survived only 6 weeks, while 3 others are alive at 48 months or more. Death was not attributed to PE in any of the patients.

\section{Discussion}

Several studies and case reports have addressed the issue of cement leakage and $\mathrm{cPE}$ in patients undergoing vertebroplasty, with conflicting conclusions.

Our literature search retrieved many papers addressing this topic; the majority consisted of case reports, mostly in non-cancer patients. However, some papers include a few cancer cases in series with a majority of non-cancer patients [12-14].

The reported frequency of $\mathrm{cPE}$ was variable. Variation in imaging modalities, screening strategies and patient populations studied contributed to this marked variation $[15,16]$. In our study, the small number of patients with cPE makes it difficult to correlate the risk of $\mathrm{CPE}$ to the number of injections performed. Other variables including site, severity of resulting deformity, body mass index (BMI), primary tumor and additional comorbidities may contribute.

In one study, chest radiographs were available in 64 of 69 percutaneous vertebroplasty procedures and, upon retrospective review, cPE was noted in only three (4.6\%) cases [17]. In another study, CT scans of the chest were obtained routinely and cPE was identified in 18 (23\%) of 78 procedures performed in patients with osteoporotic, non-malignant fractures [18].

In a more recent study, VERTOS II, chest CT was obtained for all patients post-vertebroplasty regardless of symptoms; 14 (26\%) of 54 patients had cPE and all were asymptomatic [19].

Data addressing the clinical manifestations and risk factors for cement pulmonary emboli in cancer patients are very limited, as much of the published literature involves patients with osteoporotic fractures. A few studies include small numbers of cancer patients among larger series of patients with vertebral fractures related to osteoporosis and not cancer [18-20].

Although data from the literature suggest that most patients with $\mathrm{cPE}$ as a complication of osteoporotic 
Table 2 Characteristics and outcome of patients with cement pulmonary embolism

\begin{tabular}{|c|c|c|c|c|c|c|c|c|c|c|}
\hline Number & Age & Gender & Underlying Etiology ${ }^{\mathrm{b}}$ & Primary Cancer & Location & Type of PE & Symptoms & Anticoagulation & Status & Survival (Months) \\
\hline 1 & 31 & $\mathrm{~F}$ & Malignant & Breast & $\mathrm{T} 12-\mathrm{L} 2$ & Main & $\begin{array}{l}\text { Dyspnea, } \\
\text { Tachycardia, } \\
\text { Hypoxia }\end{array}$ & No & Dead & 8.5 \\
\hline 2 & 41 & $\mathrm{~F}$ & Malignant & Breast & L1-L5 & segmental & $\begin{array}{l}\text { Dyspnea, } \\
\text { Tachycardia, } \\
\text { Hypoxia }\end{array}$ & LMWH & Dead & 1.5 \\
\hline 3 & 78 & $\mathrm{~F}$ & Osteoporosis & Lymphoma & L1 & segmental & No & No & Alive & 53 \\
\hline 4 & 55 & M & Osteoporosis & Lung & L2- L5 & Lobar & No & No & Dead & 12 \\
\hline 5 & 81 & $\mathrm{~F}$ & Osteoporosis & Lymphoma & L5 & subsegmental & No & LMWH & Alive & 48 \\
\hline 6 & 37 & M & Malignant & MM & T9-12,L1 & subsegmental & No & No & Dead & $N A^{a}$ \\
\hline 7 & 50 & $\mathrm{~F}$ & Malignant & $\mathrm{MM}$ & T5-T8 & subsegmental & No & No & Dead & 24 \\
\hline 8 & 63 & M & Malignant & MM & L1-L3 & Lobar & No & No & Dead & 20 \\
\hline 9 & 50 & M & Malignant & $\mathrm{MM}$ & L2-L4 & subsegmental & No & No & Alive & 48 \\
\hline 10 & 68 & M & Malignant & $\mathrm{MM}$ & $\mathrm{T} 12, \mathrm{~L} 1, \mathrm{~L} 2$ & subsegmental & $\begin{array}{l}\text { Dyspnea, } \\
\text { Chest pain, } \\
\text { Cough, } \\
\text { Tachycardia, } \\
\text { Hypoxia }\end{array}$ & No & Dead & 4.5 \\
\hline 11 & 60 & $\mathrm{~F}$ & Malignant & Breast & $\llcorner 4$ & subsegmental & No & Already on LMWH & Dead & 11 \\
\hline 12 & 45 & $\mathrm{~F}$ & Malignant & MM & L3-L5 & Main & Dyspnea & LMWH & Dead & 8 \\
\hline 13 & 45 & $\mathrm{~F}$ & Malignant & MM & $\mathrm{T} 12, \mathrm{~L} 1, \mathrm{~L} 2$ & Lobar & Dyspnea & LMWH & Dead & 8 \\
\hline
\end{tabular}

LMWH Low molecular weight heparin, MM Multiple Myeloma

${ }^{a} \mathrm{NA}$ : Data not available, ball in cancer patients

compression fractures were diagnosed through screening radiographic studies and remained free of symptoms or long-term adverse pulmonary sequelae [16], five (38.5\%) of our 13 patients had symptoms (dyspnea, cough, chest pain, tachycardia, hypoxia) that led to the diagnosis. While it is true that such respiratory symptoms in patients with cancer can be attributed to a variety of pulmonary disorders (lung metastasis, pleural effusions, smoking-related chronic obstructive pulmonary airway disease (COPD) or even thrombotic PE), none of the five symptomatic patients in our study had any other pathology that could explain their symptoms.

While there is no standard of care for the treatment and management of $\mathrm{CPE}$, asymptomatic individuals may be effectively managed conservatively with close clinical monitoring [21]. This conclusion is supported by the fact that none of the asymptomatic patients in our series had any clinical sequelae. However, all five symptomatic patients were fully anticoagulated. Anticoagulation can help prevent progressive pulmonary artery occlusion [22].

The increasing use of vertebroplasty and the incidence of associated symptomatic and asymptomatic cPE highlight the importance of a better understanding of this commonly encountered complication. Adequate efforts should be made to identify cancer patients who are at risk of this complication and to identify appropriate screening and therapeutic strategies.
Many questions remain unanswered. Should we recommend that routine imaging studies be performed after vertebroplasty [23]? Should we anticoagulate all asymptomatic patients diagnosed by routine imaging studies performed after the procedure? Is a location (cervical, thoracic, or lumbar vertebrae) associated with higher risk? What is the natural history of cPE? Further research is needed to address these knowledge gaps regarding $\mathrm{CPE}$ in cancer patients.

\section{Conclusions}

Cement PE, while mostly asymptomatic, is a relatively common complication following vertebroplasty. Multiple myeloma is the commonest malignancy associated with this complication. Large-scale prospective studies can help identify risk factors and clinical outcomes, and help develop better prevention and therapeutic strategies.

Acknowledgments

Not applicable.

Funding

This research received no specific grant from any funding agency in the public, commercial, or not-for-profit sectors.

Availability of data and materials

Please contact authors for data requests. 


\section{Authors' contributions}

AM: reviewed all imaging studies, drafted the manuscript and coordinated the study. NA: participated in data collection and analysis. HA: reviewed all imaging studies. SS: reviewed the literature and helped draft the manuscript. MM: participated in data analysis and drafting of the manuscript. NS and KA: Both participated in data collection and analysis. All authors read and approved the final manuscript.

\section{Ethics approval and consent to participate}

Our Institutional Review Board (IRB) determined that this retrospective analysis constitutes exempt research.

\section{Consent for publication}

Consent was obtained from the patient whose imaging studies were included in the manuscript (submitted).

\section{Competing interests}

The authors declare that they have no competing interests.

\section{Publisher's Note}

Springer Nature remains neutral with regard to jurisdictional claims in published maps and institutional affiliations.

\section{Author details}

${ }^{1}$ Department of Radiology, King Hussein Cancer Center, Amman, Jordan. ${ }^{2}$ Istishari Hospital, Amman, Jordan. ${ }^{3}$ Department of Internal Medicine, King Hussein Cancer Center, Amman, Jordan.

Received: 16 November 2017 Accepted: 25 January 2018

Published online: 08 February 2018

\section{References}

1. Melton $\sqcup$ 3rd, Kan SH, Frye MA, Wahner JW, O'Fallon WM, Riggs BL. Epidemiology of vertebral fractures in women. Am J Epidmiol. 1989;129:1000-11.

2. Vogt TM, Ross PD, Palermo L, et al. Vertebral fracture prevalence among women screened for the fracture intervention trial and a simple clinical too to screen for undiagnosed vertebral fractures. Fracture intervention trial research group. Mayo Clin Proc. 2000;75:888-96.

3. Papaioannou A, Watts NB, Kendler DL, Yuen CK, Adachi JD, Ferko N. Diagnosis and management of vertebral fractures in elderly adults. Am J Med. 2002;113:220-8.

4. Siminoski $\mathrm{K}$, Warshawski RS, Jen $\mathrm{H}$, Lee $\mathrm{K}$. The accuracy of historical height loss for the detection of vertebral fractures in postmenopausal women. Osteoporos Int. 2006;17:290-6.

5. Schlaich C, Minne HW, Bruckner T, et al. Reduced pulmonary function in patients with spinal osteoporotic fractures. Osteoporos Int. 1998;8:261-7.

6. Longo UG, Loppini M, Denaro L, Brandi ML, Maffulli N, Denaro V. The effectiveness and safety of vertebroplasty for osteoporotic vertebral compression fractures. A double blind, prospective, randomized, controlled study. Clin Cases Miner Bone Metab. 2010;7:109-13.

7. Tarsuslugil S, O'Hara R, Dunne N, et al. Development of calcium phosphate cement for the augmentation of traumatically fractured porcine specimens using vertebroplasty. J Biomech. 2013;46:711-5.

8. Brodano GB, Amendola L, Martikos K, et al. Vertebroplasty: benefits are more than risks in selected and evidence-based informed patients. A retrospective study of 59 cases. Eur. Spine J. 2011:20:1265-71.

9. Mathis J, Deramond H, Belkoff S. Percutaneous Vertebroplasty and Kyphoplasty (Second Edition) Springer 2006; pp 3-5. ISBN 0-387-29078-8.

10. Katsumi K, Hirano T, Watanabe K, et al. Surgical treatment for osteoporotic thoracolumbar vertebral collapse using vertebroplasty with posterior spinal fusion: a prospective multicenter study. Int Orthop. 2016;40:2309-15.

11. Yeom JS, Kim WJ, Choy WS, Lee CK, Chang BS, Kang JW. Leakage of cement in percutaneous vertebroplasty for painful osteoporotic compression fractures. J Bone joint Surg Br. 2016;85:83-9.

12. Baumann A, Tauss J, Baumann G, Tomka M, Hessinger M, Tiesenhausen K. Cement embolization into the vena cave and pulmonal arteries after vertebroplasty: interdisciplinary management. Eur J Vasc Surg. 2006:31:558-61.

13. Duran C, Sirvanci M, Aydoğan M, Ozturk E, Ozturk C, Akman C. Pulmonary cement embolism: a complication of percutaneous vertebroplasty. Acta Radiol. 2007:48:854-9.
14. Habib N, Maniatis T, Ahmed S, et al. Cement pulmonary embolism after percutaneous vertebroplasty and kyphoplasty: an overview. Heart Lung. 2012;41:509-11.

15. Potet J, Weber-Donat G, Curis E, et al. Incidence of pulmonary cement embolism after real-time CT fluoroscopy-guided vertebroplasty. J Vasc Interv Radiol. 2013;24:1853-60.

16. Venmans A, Lohle PN, van Rooij WJ, Verhaar HJ, Mali WP. Frequency and outcome of pulmonary polymethylmethacrylate embolism during percutaneous vertebroplasty. AJNR Am J Neuroradiol. 2008;29:1983-5.

17. Choe DH, Marom EM, Ahar K, Truong MT, Madewell JE. Pulmonary embolism of polymethyl methacrylate during percutaneous vertebroplasty and kyphoplasty. AJR Am J Roentgenol. 2004;183:1097-102.

18. Kim YJ, Lee JW, Park KW, et al. Pulmonary cement embolism after percutaneous vertebroplasty in osteoporotic vertebral compression fractures: incidence, characteristics, and risk factors. Radiology. 2009;251:250-9.

19. Venmans A, Klazen CA, Lohle PN, et al. Percutaneous vertebroplasty and pulmonary cement embolism: results from VERTOS II. Am J Neuroradiol. 2010;31:1451-3.

20. Luetmer MT, Bartholmai BJ, Rad AE, Kallmes DF. Asymptomatic and unrecognized cement pulmonary embolism commonly occurs with vertebroplasty. Am J Neuroradiol. 2011;32:654-7.

21. Krueger A, Biliemel C, Zettl R, Ruchholtz S. Management of pulmonary cement embolism after percutaneous vertebroplasty and kyphoplasty: a systematic review of the literature. Eur Spine J. 2009;18:1257-65.

22. Tozzi P, Abdelmoumene Y, Corno AF, Gersbach PA, Hoogewoud HM, von Segesser LK. Management of pulmonary embolism during acrylic vertebroplasty. Ann Thorac Surg. 2002;74:1706-8.

23. Bliemel C, Buecking B, Struewer J, Piechowiak El, Ruchholtz S, Krueger A. Detection of pulmonary cement embolism after balloon kyphoplasty: should conventional radiographs become routine? Acta Orthop Belg. 2013; 79:444-50.

\section{Submit your next manuscript to BioMed Central and we will help you at every step:}

- We accept pre-submission inquiries

- Our selector tool helps you to find the most relevant journal

- We provide round the clock customer support

- Convenient online submission

- Thorough peer review

- Inclusion in PubMed and all major indexing services

- Maximum visibility for your research

Submit your manuscript at www.biomedcentral.com/submit
Ciomed Central 